\title{
Educational Innovation
}

\author{
María Luisa Sein-Echaluce \\ University of Zaragoza \\ María de Luna, 3 \\ 50014-Zaragoza \\ +34976761979 \\ mlsein@unizar.es
}

\author{
Ángel Fidalgo-Blanco \\ Technical University of Madrid \\ Rios Rosas, 21 \\ 28003-Madrid \\ +34913367046 \\ angel.fidalgo@upm.es
}

\author{
Neuza Pedro \\ University of Lisbon \\ Alameda da Universidade \\ 1649-013 Lisboa \\ +351217943690 \\ nspedro@ie.ulisboa.pt
}

\begin{abstract}
An effective way to understand, improve and apply educational innovation is through the analysis of good practices. Sharing the acquired knowledge in the development and application of good practices helps teachers to implement educational innovation. Good practices help to reduce the teachers' effort and to contribute structural to the educational institutions. This paper presents the good practices of the track "Educational Innovation" at the conference TEEM'15. They are organized in 5 lines corresponding to tendencies on educational innovation: Learning Communities, Learning personalization/Adaptive learning, Training and assessment of teamwork, New learning models and Innovation in online learning methods.
\end{abstract}

\section{Categories and Subject Descriptors}

- Applied computing $\rightarrow$ Education

\section{Keywords}

Educational innovation; Learning communities; Adaptive learning; Teamwork competence; Learning contents management systems.

\section{INTRODUCTION}

Although hard to delimitate the concept of educational innovation is been increasingly adopted in the education and training fields, more strongly in this last few years. In this track we embrace the following definition for educational innovation: a particular idea, project or strategy that is taken in to improve the educational process and that reveals to be new and/or to promote changes in the context that adopts. This definition inherently includes in the educational innovation the following characteristics: i) an intentional basis, as any innovation has to be deliberately adopted, ii) a transformative nature for the context in question, iii) the chase for an incremental solution, and iv) the production of improvements in the teaching-learning processes.

Permission to make digital or hard copies of all or part of this work for personal or classroom use is granted without fee provided that copies are not made or distributed for profit or commercial advantage and that copies bear this notice and the full citation on the first page. Copyrights for components of this work owned by others than the author(s) must be honored. Abstracting with credit is permitted. To copy otherwise, or republish, to post on servers or to redistribute to lists, requires prior specific permission and/or a fee. Request permissions from Permissions@acm.org. TEEM '15, October 07 - 09, 2015, Porto, Portugal Copyright is held by the owner/author(s). Publication rights licensed to ACM. ACM 978-1-4503-3442-6/15/10 ..\$15.00

DOI: http://dx.doi.org/10.1145/2808580.2808592
Actually, the majority of teachers focus the educational innovation on the students. Teachers usually implement innovative experiences in order to improve learning, to increase students' motivation or to promote an active participation of students in their own learning process. In addition, teachers undertake educational innovation in an isolate way, with a local scope and without the required time to check their effects and to develop proposals that are useful and transferable.

Yet, there are educational innovations with a more transversal and global scope, such as the massive open online courses (hereinafter MOOCs). This type of innovation usually grows up very fast and generates intense debates at the beginning $[1 ; 2]$ and therefore requires multiple studies that can understand their benefits, solve their inherent problems (such as the high dropouts and the validity of certificates, in the example of MOOCs) and provide its consolidation.

Other type of educational innovation is based on research for the inclusion of new methodologies. This type is framed on the called "tendencies in innovation" and it incorporates learning analytics [3], gamification [4], informal training [5], etc. This type of innovation requires interdisciplinary teams, financial resources, cooperation between research teams and practitioners, as well as the adoption of work approaches that are based on the results provided by R\&D\&i projects.

It is also relevant to see that some "old" methods, such as collaborative learning/teamwork and personalized/adaptive learning, whose benefits are widely proved but that require enormous effort from the teachers to follow up, are having a new relevancy with the use of the information and communication technologies (ICT) [6; 7].

The educational innovation can be seen as a crossroads between the different types of innovation mentioned above [8]. At this moment the digital university is real, it become an academic reality but it did not necessarily transformed the different aspects of learning in higher education. Educational innovation is the engine that really transforms learning, but for the transformation process to be effective, it must synchronize the new academic services with the new learning methods.

In any case, independently of the type of educational innovation we are considering, it is necessary to spread the experiences and research developed around this topic. In that sense, the track of Educational Innovation in TEEM15 has two main objectives: to create crossroads between different types of innovation and to contribute with "oil" to the motion of the learning transformational engine [9]. 
To this track converge innovations applied in the classroom, transversal innovations which need analysis of feasibility, and R\&D\&i projects on educational innovation. All of them are organized in the different lines of the track explained in the next section.

The relevancy of the rest of tracks in TEEM15 should also be mentioned. In these it is possible to deepen in the knowledge of innovative didactic approaches, as well as new tools and technologies which are being currently used in educational innovation. The publication of the papers in ACM digital contributes to a wider spread of this topic. It helps not only the attenders to the conference to reflect on the topic but it also benefits the wider research community with the knowledge, experience and work shared in TEEM15 conference.

\section{LINES OF WORK}

This track wants to congregate, in five lines of work on educational innovation, the results of the application of technologies/methodologies to solve real needs in education. Other trending lines in educational innovation, such as learning analytics, gamification or informal learning are the specific subject of other tracks in TEEM15.

Other lines that are currently trending topics are:

- Line 1. Learning Communities. Cooperation, informal and formal learning communities supported by web 2.0 environments. The society is increasingly using this type of training and "online learning communities" are arising. It highlighted the need to integrate these tools- online community and social networks-, as well as multicultural cooperation and methodologies of nonformal and informal training in the academic environment.

- Line 2. Learning personalisation/Adaptive learning. Adaptive systems try to accommodate the specific conditions of each student or teacher and effective respond to it by improving the learning process. ICT are the tools to adapt the access to resources, training plan or training strategy to the students.

- Line 3. Training and assessment of teamwork. Cooperation and teamwork are one of the most demanded skills in todays' working sector. On the other hand, the quality evaluation agencies are currently demanding to universities the evidences of the teamwork competency of students.

- Line 4. New learning models. The integration of new technologies, processes and services generate new models which are applicable to learning and education. The audiovisual technology, the semantic repositories and the knowledge management systems generate new learning models that can be applied and adapt to any educational context.

- Line 5. Innovation in online learning methods (massive or not). The online learning content management systems are widely used in both face-to-face training and distance learning, and new models are emerging for academic and social settings. The massive open online courses (MOOC) are a revolution in terms of higher education targets, yet serious studies in this topic need to be conducted and discussed.

\section{ACCEPTED PAPERS}

17 papers have been accepted in this track and they are distributed, in the different lines, in the following manner: three paper in line 1 , three papers in line 2 , two papers in line 3 , four papers in line 4 and five papers in line 5.

\subsection{Papers in Line 1. Learning Communities}

26- Teacher attitudes towards ICT in the context of inclusive education. This work studies how teachers use and integrate the 'Information and Communication Technologies' (ICT) in inclusive classrooms. It also identifies the factors that promote good educational practices supported by ICT. The results show that teachers present positive attitude towards ICT. Networks of schools are presented as important to develop good educational practice with the support of ICT.

42- Monitoring technologies in Suricata model for the formal and informal learning areas. This paper presents the results of a research on the Suricata model in a formal and informal learning environment. For the formal setting, a basic computer course is analyzed at the Faculty of Translators and Interpreters. Two groups were analyzed with the same subject. For the results a platform of formal education itself, based on Moodle and social network analysis was used. The resident plugin allowed the conversion of files into Pajek format. The analysis of these files in Pajek format provides the results presented in this article. For the informal environment an open source software, called Elgg, was used.

71- Teaching Sustainability in a Multicultural Environment. Aiming at a higher level of internationalization and having in mind that students could gain from an intensive and multicultural experience, ISEP organized its first Engineering for Sustainable Development Summer Course (E4SD), in July 2014. With a set of modules taught by experienced teachers in different topics of sustainability, the course adopted a 'Problem-based learning' (PBL) approach and was organized in a very informal model. A total of 8 Korean and 8 Portuguese students from different areas of scientific knowledge attended this course. They were able to interact and develop ties with each other and with the teachers involved in the course, while learning and applying the fundamental skills on sustainability.

\subsection{Papers in Line 2. Learning personalisation/Adaptive learning}

27- Mobile Personal Learning Environments: conceptualization and structure. The massive diffusion and use of Web 2.0 tools by students are influencing their particular ways of learning. Also, the increase in the access of people to the World Wide Web is a reality and the use of mobile electronic devices (smartphones and tablets) in education evidence some positive results. This article conceptualizes the Mobile Personal Learning Environments (mPLE) concept and proposes a structure for further design and implementation in higher education context through the use of Web 2.0 tools.

66- Mobile Acceptance among Pre-Service Teachers: A Descriptive Study Using a TAM-Based Model. In this communication the results of a descriptive study on the acceptance of mobile technologies among the pre-service teachers undergoing training in the University of Salamanca are presented. The population for this study is composed by 678 students from the Primary Education Bachelor's Degree, to whom have been handed a questionnaire based on the Technology Acceptance Model (TAM) and expanded with the constructs of self-efficacy and mobile device anxiety. The results show favourable disposition of pre-service teachers towards the use of these devices in their teaching practice. No significant differences were 
found according to the year the students were in, but some differences were observed based on the students' gender.

85- Design of adaptive experiences in Higher Education based on a Learning Management System. In this paper, several experiences on adaptive learning at several Degrees of Engineering are shown. Different contexts (Problems Based Learning, final works of Grade, b-learning courses and Massive Open Online Courses) require different methodologies. These experiences have been based on "adaptive pills" (needs of adaptivity) and the technological solutions are provided by the Learning Management System Moodle. Several measurement tools have been applied which provided good results in terms of students' academic achievement and satisfaction.

\subsection{Papers in Line 3. Training and assessment of teamwork}

70- Collaborative Learning using tablets in EFL to develop Oral Communication. This paper describes a study about Teaching English as a Foreign Language (TEFL) and the use of tablets, which implied implementing a didactic unit using iPad devices. Several educational resources were produced by teachers and students. The impact of this unit on the students' oral communication development, motivation, as well as on teachers' adoption of tablets, was evaluated. Several measurement tools were used to verify good indicators of the impact of the project concerning the three research questions.

86- A repository of students' resources to improve the teamwork competence acquisition. This work presents the initial conditions of students, in terms of contents sharing and teamwork competence, previously to the implementation of a quasiexperimental research. The final aim of this research is to prove the benefits in terms of effectiveness on the students learning on teamwork competence, when they reuse resources created by other students and managed on a specific knowledge management system.

\subsection{Papers in Line 4. New learning models}

19- Exploring the use of Quick Response Codes: accessing videos in the laboratory. The aim of this research is to evaluate the importance that undergraduate engineering students attribute to instructional videos that explain the operating procedure of laboratory apparatus, and their reaction to the possibility of accessing them with quick response (QR) codes. Results show students attributed some importance to the videos and that the QR codes in the laboratory are very helpful as a mean to quickly and easily access the videos.

83- Educational Innovation Management. A Case Study at the University of Salamanca This paper is devoted to present the implantation of a repository for educational innovation projects management at the University of Salamanca in Spain. This repository stores the selected best practices of educational innovation in this University and classifies them according a set of indicators that have been previously agreed. The paper explains the processes of defining the indicators and their application to a set of selected projects that have been stored in the repository.

84- Design of an innovative approach based on Service Learning for Information Technology Government Teaching. Service learning is an approach that integrates social service into an academic setting. This paper present a design for a course that uses a service learning based orientation to teach Information Technology Government based on the experiences of two different Informatics Masters' Degree in two different universities.

106- Analysis of Knowledge Management Experiences in Spanish Public Administration. Under the development of the Digital Society and with the aim of achieving a true transition from the Information Society to the Knowledge Society, ICTs play a capital role in educational and knowledge management processes in any kind of entity, from Small and Medium-sized Enterprises (SME) to the Public Administration (PA). The purpose of this paper is to provide an analysis about the knowledge management in the Spanish Public Administration, composed by a huge amount of research centers and public companies, through the study of several real cases developed in different public organisms.

\subsection{Papers in Line 5. Innovation in online learning methods (massive or not)}

8- High vs. low intensity courses. Student Technological Behavior. This paper discusses the design of two educational proposals based on Project-Based Learning (PBL) and the use of Information and Communication Technologies (ICT). Both courses are focused on the spatial representation of 3D models in architectural training. The study focuses on comparing the preparation and student motivation in two different educational scenarios: a low-density experience where 3-4 applications are used, and a high density "crash course" using about 15 different applications and techniques. For the analysis of the results a quantitative approach was adopted to compare both scenarios and review the differences of students' motivation and initial preparation.

16- Developing a VLE to Enable the Innovative Learning of English Pronunciation. The authors present the outcomes of a quantitative study carried out during the academic year 2010/2011 at the Pontifical University of Salamanca (Spain). This study explores the validity and benefits of an innovative technological model implemented in a blended-learning group. To investigate this issue, the following hypotheses were raised: the English phonetic, the phonology learning level, as well as the students' satisfaction will be higher with the implementation of this model. The obtained results confirm these hypotheses and show the potential of the model to improve the teaching-learning process.

17- An Optimal Use of a Blended-Learning Model to Improve Grammatical Competence. The study focuses on learners' perceptions for learning English grammar in the course of English Morphosyntax at a graduate level at the Pontifical University of Salamanca that is offered via a blended instructional delivery mode. The study utilizes a quantitative method approach. The learners' high satisfaction towards the blended instructional delivery mode reveals that the model implemented provides a satisfying experience.

22- Virtual Heritage Territories: Augmented Reality and Pedestrian Navigation through educational implementation. This paper presents the creation and educational effectiveness of a digital learning module related to the implementation of Mobile Pedestrian Navigation and Augmented Reality (MPN-AR) features, developing educational processes linked to the territorial information and historical-culture heritage corresponding to the cities of Salamanca (Spain) and Santiago (Chile).

95- Identifying Educational Innovation Characteristics. The university is supporting educational innovation through several plans and policies. Frequently that planning is top-bottom, 
designing services, rules, financial aid announcements, conferences and repositories. However, the most important facts of the educational innovation are the activation, application and exchange of experience between teachers. For this objective it is required a bottom-up perspective, coming from faculty and students. This work uses a survey validated to obtain indicators associated to the development of an educational innovation project. These variables are useful to boost, organize and improve the policies in educational innovation.

\section{CONCLUSIONS}

This track presents a selection of good practices on educational innovation which cover a broad spectrum of technics, methods, processes, services and results. Good practices constitute an essential element to go forward in the educational innovation path, allowing teachers to gather relevant information from the experience already obtained by other teachers.

Sharing good practices is crucial to improve Education and doing it in a scientific, cooperative and international context contributes to boost the educational innovation and acts as a generator of new knowledge.

\section{ACKNOWLEDGMENTS}

The chairs of this track for Educational Innovation wish to acknowledge and thank the hard work of the Scientific Committee for this track. They reviewed, recommended and evaluated the submitted papers. We also wish to thank the organizing committee of TEEM15 for their great coordination, management and integration of all the tracks; thanks to them the organization of this track has been made possible.

\section{REFERENCES}

[1] Martínez Abad, F., Rodríguez Conde, M.J., and GarcíaPeñalvo, F.J. 2014. Evaluación del impacto del término "MOOC" vs "eLearning" en la literatura científica y de divulgación. Profesorado. Revista de currículum y formación del profesorado. 18, 1, 185-201.

[2] Fidalgo-Blanco, A., Sein-Echaluce, M.L., García-Peñalvo F.J. 2015. Methodological approach and technological framework to break the current limitations of MOOC model. Journal of Universal Computer Science, 21, 5, 712-734.
[3] Fidalgo-Blanco, A., Sein-Echaluce, M.L., García-Peñalvo F.J. and Conde, M.A. 2015. Using learning analytics to improve teamwork assessment, Computers in Human Behavior, 47, 149-156. DOI: http://doi.org/10.1016/j.chb.2014.11.050

[4] Llorens Largo, F., Molina Carmona, R., Gallego Durán, F., Villagrá Arnedo, C., Aznar Gregori, F. 2013. ABPgame: un videojuego como proyecto de aprendizaje coordinado para varias asignaturas. Actas Congreso Internacional de Aprendizaje, Innovación y Competitividad. Novembre. Available at http://www.dmami.upm.es/dmami/documentos/liti/ACTAS_ CINAIC_2013.pdf

[5] García-Peñalvo, F.J., Johnson, M., Ribeiro Alves, G., Minovic. M., and Conde-González, M. Á. 2014. Informal learning recognition through a cloud ecosystem, Future Generation Computer Systems, 32, 282-294.

[6] Fidalgo, A. Lerís, D., Sein-Echaluce, M.L. and García Peñalvo F.J. 2015. Monitoring Indicators for CTMTC: Comprehensive Training Model of the Teamwork Competence. International Journal of Engineering Education, 31(3), 829-838.

[7] Lerís, D., and Sein-Echaluce, M. L. 2011. La personalización del aprendizaje: un objetivo del paradigma educativo centrado en el aprendizaje. Arbor: Ciencia, pensamiento y cultura, 187 (3), 123-134 DOI:10.3989/arbor.2011.Extra3n3135http://arbor.revistas.csic.es/index.php/arbor/article/vie wFile/1417/1426.

[8] Seminario "La innovación docente en la encrucijada". September 2012. Available at http://cinaic.com

[9] Fidalgo-Blanco, A., Sein-Echaluce, M. L., and GarcíaPeñalvo, F. J. 2015. Epistemological and ontological spirals: From individual experience in educational innovation to the organisational knowledge in the university sector. Program: Electronic library and information systems, 49(3), 266-288. DOI: http://dx.doi.org/10.1108/PROG-06-2014-0033. 